\title{
Neighbourhood-level air pollution and greenspace and inflammation in adults
}

\begin{abstract}
Inflammation has been proposed as a pathway from adverse physical environments to poor physical and mental health. We estimated longitudinal associations of neighbourhood-level air pollution and greenspace with individual-level inflammation (measured with C-reactive protein and fibrinogen), using data from over 8,000 adults living in England and Wales who participated in Understanding Society. Using linear regression, we found that neighbourhoodlevel nitrogen dioxide predicted later levels of fibrinogen, but not C-reactive protein. Area air pollution, but not area greenery, appears to predict inflammation, even after accounting for social deprivation in the area.
\end{abstract}

Keywords: air pollution; greenspace; inflammation; neighbourhoods; Understanding Society

Funding: This work was supported by the British Academy (grant number SG170593).

Acknowledgements: We would like to thank Sujit Sahu for providing the air pollution estimates analysed in this paper, available from the website linked to Mukhopadhyay and Sahu (2017). 
There is an increasing amount of evidence for the role of two aspects of the built environment, air pollution and greenery, in individual health. For one, outdoor air pollution has been associated with adverse respiratory, cardiovascular and mental health outcomes in adulthood (Guarnieri, \& Balmes, 2014; Lim et al., 2012; Oudin et al., 2016; Perera et al., 2011; 2012). Whereas air pollution is considered to be health-limiting, the amount of greenspace is considered to be health-enhancing (Groenewegen, 2018). Indeed, greenspace in the neighbourhood has been linked with better physical and mental health in adults (Alcock, White, Wheeler, Fleming, \& Depledge, 2014; Hartig, Mitchell, \& de Vries, 2014; Mitchell, Richardson, Shortt, \& Pearce, 2015; Ward Thompson \& Aspinall, 2011).

Air pollution and greenspace are inversely related. There is growing evidence that green spaces can contribute to the reduction of air pollution levels in urban settings. In their meta-analysis, Zupancic, Westmacott and Bulthuis (2015) found that all types of green spaces, from small green walls and roofs to large urban forests, appear to improve outdoor air quality. With more land devoted to greenery, there is less land available for pollutiongenerating processes and combustion. Additionally, trees capture large amounts of airborne gaseous, particulate and aerosol pollutants thereby reducing their concentration in the air (Beckett, Freer-Smith \& Taylor, 1998; Freer-Smith \& Broadmeadow, 1996; Freer-Smith et al., 1997; Nowak et al., 1997; Powe \& Willis, 2004). Therefore, woodlands and the presence of trees and, in general, the amount of greenspace in the environment can improve air quality. Nevertheless, only a few studies have included neighbourhood measures of both air pollution and greenspace in exploring their independent effects on health (Chaparro, Benzeval, Richardson, \& Mitchell, 2018; Midouhas, Kokosi, \& Flouri, 2018).

Furthermore, few studies have examined the relative contributions of air pollution and greenspace to inflammation, the body's response to injury or stress, a key proposed biological pathway linking neighbourhood physical environmental factors to health (Howren et al., 
2009; Kiecolt-Glaser et al., 2015). Evidence shows that inflammation is strongly related to a wide range of physical health outcomes including cardiovascular disease, hypertension and type 2 diabetes (Brunner et al., 2008; Irwin \& Cole, 2011; Ridker, Buring, Cook, \& Rifai, 2003; Ridker, Rifai, Rose, Buring, \& Cook, 2002; Sesso, Buring, Rifai, Blake, Gaziano \& Ridker, 2003). Inflammation has also been linked with psychological distress (Smith, 1991). Studies have found higher levels of inflammatory markers including interleukin 6 (IL-6) and C-reactive protein (CRP), an acute phase protein, among patients with psychiatric disorders (Howren et al., 2009; Kiecolt-Glaser et al., 2015).

Researchers have explored in separate studies the role of air pollution in inflammation, with inconsistent findings (Hajat et al., 2015). Thompson et al. (2009) found that ozone and sulphur dioxide $\left(\mathrm{SO}_{2}\right)$ predicted IL-6 but not fibrinogen, another acute-phase protein, in a small sample of adults. Chuang, Chan, Su, Lee and Tang (2007) showed that in a small sample of university students in Taipei, those exposed to high levels of ozone and $\mathrm{SO}_{2}$ had elevated fibrinogen, but they did not find effects of other pollutants including nitrogen dioxide $\left(\mathrm{NO}_{2}\right)$. A study by Chaparro et al. (2018) identified a cross-sectional association between both carbon monoxide and $\mathrm{SO}_{2}$ (but not nitrogen dioxide $\left[\mathrm{NO}_{2}\right]$ or particulate matter $[\mathrm{PM}])$ and higher CRP in a UK adult population sample. Conversely, several studies have found no relationships between any air pollutants explored and CRP or fibrinogen in adults (Forbes et al., 2009; Lanki et al., 2015; Rudez et al., 2009). A meta-analysis (Li, RittenhouseOlson, Scheider, \& Mu, 2012) showed that there is inconsistent evidence for a relationship between exposure to PM and higher concentrations of CRP in healthy adult samples (Hoffman et al., 2009) and also that PM-induced CRP responses have not been found in adults with chronic inflammatory conditions (Li et al., 2012). Li et al. (2012) suggest the latter may be due to their use of anti-inflammatory medications. The few studies examining exposures to air pollution over longer periods show more promising results. A study 
(Viehmann et al., 2015) using data from a German population cohort of over 4,000 individuals found links with increased PM and elevated CRP but not fibrinogen. Among randomised controlled trials, only one with a longer intervention phase showed an effect of PM exposure on concentrations of CRP (Li et al., 2012).

On the other hand, greenspace may inhibit the elevation of inflammation as it has been shown to directly lower stress levels (de Vries, van Dillen, Groenewegen, \& Spreeuwenberg, 2013; Thomson et al., 2012). It is also related to many physical health outcomes including decreased salivary cortisol, heart rate and diastolic blood pressure, lower risk of cardiovascular mortality and increased incidence of self-rated good health (TwohigBennett \& Jones, 2018). The exposure to a diverse variety of bacteria found in natural areas may reduce inflammation and have immunoregulatory benefits (Rook, 2013). Moreover, greenspace may promote physical activity (Coombes et al., 2010), which is shown to reduce inflammation (Ertek \& Cicero, 2012). To our knowledge, only one study has explored the relationship between the amount of greenspace in one's neighbourhood and markers of inflammation. Chaparro et al. (2018) examined both neighbourhood air pollution and greenspace as mediators of the association between neighbourhood deprivation and a range of health biomarkers including inflammation in adults, measured with CRP. As part of their analyses, they found higher concentrations of carbon monoxide and $\mathrm{SO}_{2}$ were significantly related to higher CRP, whereas more greenspace was associated with lower CRP. They used data on individuals living in England, Wales and Scotland and participating in Understanding Society, a UK cohort of roughly 40,000 households, tracked from around 2009, the dataset used in the present study. However, they did not explore fibrinogen as an indicator of inflammation. Moreover, like most of the aforementioned studies, they did not analyse associations longitudinally. Longitudinal data allows researchers to capture duration of time individuals have spent in environments with particular levels of exposure, capturing any 
moves from one environment to another. Moreover, longitudinal studies, compared with cross-sectional studies, can more effectively reduce self-selection in residential environments by allowing for the adjustment of the characteristics of individuals before change of the environment (in this case, due to household moves). In addition, the abovementioned studies exploring area effects did not use air pollution estimates for small geographical areas in order to capture more immediate levels of pollution around one's home.

In the present study, we explored the association between neighbourhood-level $\mathrm{NO}_{2}$ and greenspace and two markers of inflammation - CRP and fibrinogen - in a nationally representative adult sample in England and Wales. We used data from Understanding Society (US), a UK cohort of roughly 40,000 households, tracked from around 2009. We used novel model-based estimates of $\mathrm{NO}_{2}$ in small areas (Lower layer Super Output Areas [LSOAs]) for the years 2009-2011 (aligned with waves 1-2 of US). $\mathrm{NO}_{2}$ is a gaseous pollutant mainly emitted from road traffic (particularly diesel engines) and energy production processes. In the $\mathrm{UK}$, the level of $\mathrm{NO}_{2}$ has regularly exceeded the legal levels set by EU air quality standards $\left(40 \mu \mathrm{g} / \mathrm{m}^{3}\right)$, such as those set out in the EU Ambient Air Quality Directive and the fourth Daughter Directive. This has become a major concern for citizens as well as policymakers, particularly in London where levels are highest. Hence, identifying $\mathrm{NO}_{2}$ effects on health has important implications for UK transport policy.

\section{Method}

\section{Sample}

Understanding Society is a longitudinal study that follows annually over 40,000 households (at wave 1) in the United Kingdom. The Understanding Society sample consists of the larger General Population Sample (GPS), a stratified clustered random sample of households recruited in 2009-2010 (wave 1) and three other samples: the Ethnic Minority Boost Sample, the former British Household Panel Survey (BHPS) sample and the Immigrant 
and Ethnic Minority Boost Sample. There have been eight waves of interviews thus far. Measures of the biomarkers included in our study - including CRP, fibrinogen and body mass index - were taken during a nurse visit approximately after the main wave 2 interview (GPS participants) or the main wave 3 interview (BHPS participants) (McFall et al., 2014).

Respondents eligible to participate in the nurse visit were those who had taken part in the main interview, were aged 16+ years, lived in any of four countries of the UK (England, Wales, Scotland, and Northern Ireland), and were not pregnant. Further details of the sampling and the survey timeline can be found at https://www.understandingsociety.ac.uk/documentation/.

The current study utilised a sample of GPS ${ }^{1}$ individuals aged $21+$ years (ages ranged 21102 years) who participated in the biomarkers measurement at wave 2, had both fibrinogen and CRP data, were living in England or Wales at both waves 1 and 2 (the UK countries where we had small-area air pollution data available and linked in) and, finally, had air pollution data at both waves 1 and $2(\mathrm{n}=8,179)$. In this sample, 3,590 $(44 \%)$ participants were males and 4,589 (56\%) were females.

\section{Measures}

\section{Inflammatory markers at wave 2}

C-reactive protein (CRP) was analysed from serum using the $\mathrm{N}$ latex CRP mono assay on the Behring Nephelometer II Analyzer (Dade Behring, Milton Keynes, UK). Intra and inter assay coefficients of variation were less than $2 \%$. Systemic inflammation is defined as CRP $>3 \mathrm{mg} / \mathrm{L}$ levels. As per previous research, participants with CRP levels higher than 10

\footnotetext{
${ }^{1}$ Geographical information has not been harmonised for BHPS participants yet. As they participated in the nurse assessment at wave 3, only GPS participants who took part in the nurse assessment at wave 2 are included in our sample.
} 
$\mathrm{mg} / \mathrm{L}$ (5.6\% of the analytic sample) (likely due to infection) were excluded. CRP was log transformed and used as a continuous variable.

Fibrinogen was analysed from citrate plasma samples using a modification of the Clauss thrombin clotting method on the IL-ACS-TOPS analyser. Intra and inter-assay coefficients of variation were less than $7 \%$. Fibrinogen was used as a continuous variable as there are no established clinical cutpoints and was also log transformed for analyses, given its skewed distribution.

Neighbourhood air pollution and greenspace at waves 1 and $2^{2}$

Neighbourhood air pollution was measured with modelled-based estimates of annual concentrations of $\mathrm{NO}_{2}$ in micrograms per cubic meter of air $\left(\mu \mathrm{g} / \mathrm{m}^{3}\right)$. Estimates were for LSOAs where cohort members lived in England and Wales (Mukhopadhyay \& Sahu, 2017) from 2009-2011. LSOAs are built from Output Areas (the smallest standard areas of UK geography) and typically include about 600 homes and 1,500 residents. (Output Areas are built from postcode units.) Mukhopadhyay and Sahu (2017) modelled air pollution data collected from the 144 active Automatic Urban and Rural Network (AURN) stations in England and Wales. AURN is the UK's largest automatic monitoring network and is the main network used for compliance reporting against the Ambient Air Quality Directives (http://ukair.defra.gov.uk/networks). The best geostatistical model obtained by Mukhopadhyay and Sahu (2017) was used to predict $\mathrm{NO}_{2}$ at the corners of 1-kilometer grid-squares covering

\footnotetext{
${ }^{2}$ Data linkage for all neighbourhood variables was done using geographical codes (ward and LSOA codes) which required a special license and were provided to us by Understanding Society (the data owner). These codes had already been linked with the participants' postcodes by the data owner. The variable that specifies whether the family changed address can be found in the publicly available data files.
} 
England and Wales. These data were then used to obtain estimates of $\mathrm{NO}_{2}$ concentrations at the LSOA-level ${ }^{3}$. A one-unit increase in $\mathrm{NO}_{2}$ is an increase of $1 \mu \mathrm{g} / \mathrm{m}^{3}$.

Neighbourhood greenspace was measured with data from the Multiple Environmental Deprivation Index (MEDIx; http://cresh.org.uk/cresh-themes/environmentaldeprivation/medix-and-medclass/). MEDIx is an ordered measure of physical environment deprivation which represents the balance of pathogenic and salutogenic characteristics in a ward level (Richardson et al., 2010). One of the components of the MEDIx is the amount of greenspace across the UK at CAS (Census Area Statistics) ward-level. CAS wards were created for the 2001 Census

(https://www.ons.gov.uk/methodology/geography/ukgeographies/censusgeography\#statistical -wards-cas-wards-and-st-wards). The average population is around 5,500, though counts can vary substantially. The amount of greenspace was measured in MEDIx by combining land use data from the Coordination of Information on the Environment (CORINE) (EEA, 2000) and the 2001 Generalised Land Use Database (GLUD; Office of the Deputy Prime Minister, 2005). CORINE is a land cover dataset from 2000 for the whole of the UK, derived from remotely sensed satellite imagery. It does not capture smaller green spaces (the smallest area mapped in the UK was roughly 1 ha). Consequently, it is only sensitive to larger green spaces such as parks. GLUD classifies land use at high geographical resolution (across England only) into nine categories (greenspace, domestic gardens, fresh water, domestic buildings, non-domestic buildings, roads, paths, railways, and other). GLUD estimates include all vegetated areas larger than $5 \mathrm{~m}^{2}$ in an area (except for domestic gardens), regardless of their

\footnotetext{
${ }^{3}$ For each LSOA, Mukhopadhyay and Sahu (2017) identified the grid cells' corners that fall inside that LSOA. They then took simple averages to arrive at the LSOA level estimates. To obtain uncertainty of the estimates they used the Markov Chain Monte Carlo (MCMC) output at each of the grid corners falling within a particular LSOA. MCMC methods, being iterative, produce LSOA aggregated estimates of a particular pollution level at each of its iteration. Those iterative estimates were then used to obtain an estimate of the uncertainty of each LSOA-level estimate of exposure to air pollution.
} 
accessibility (public or private). CORINE and GLUD were used together to produce, for MEDIx, a dataset estimating amount of greenspace for each ward in the UK (Richardson \& Mitchell, 2010). See more about this here: https://cresh.org.uk/cresh-themes/green-spacesand-health/ward-level-green-space-estimates/. An increase in one-unit of greenspace is equivalent to an increase in one percentage point of greenspace._In our sample in England and Wales (spanning both urban and rural areas), the percentage of greenspace per ward ranges from $11 \%$ to $97 \%$.

\section{Covariates}

Key covariates were neighbourhood deprivation and urbanicity, age in years when inflammation was measured, gender, socio-economic individual and household factors (i.e., degree qualification, marital status, housing tenure and household composition) and healthrelated behaviours and conditions when inflammation was measured. All of these factors are important for reducing possible confounding, including biases associated with selective sorting into neighbourhoods.

Neighbourhood deprivation at waves 1 and 2 was measured with the 2011 Carstairs index which measures material deprivation in LSOAs (Carstairs \& Morris, 1989; Wheeler, 2014). Carstairs scores comprise an unweighted combination of four census variables: Unemployment, overcrowding, car ownership and low social class (Carstairs \& Morris, 1989). Each variable was standardised (z-scored). The resulting z-scores for each variable were summed to give a single deprivation score for that LSOA. An increase in the Carstairs score is associated with more deprivation. Urbanicity at waves 1 or 2 was measured with a household indicator of whether the address lies within urban settlements (i.e., with a population of 10,000 or more) or not. 
Degree was measured by whether participants had obtained a university degree or not. Marital status was measured by whether participants were partnered (married or in civil partnership) or not. Housing tenure was measured by whether the respondent owned a home (outright or with a mortgage) or not. Household composition was measured by whether respondents were living alone or with other people.

The health-related behaviours and conditions were body mass index (BMI), smoking status, alcohol consumption, having cardiovascular disease (CVD) or diabetes, having asthma, having bronchitis and having cancer. Current smoker indicated whether the participant was a current, regular smoker (of at least one cigarette per week) compared to former regular smoker or having never been a regular smoker. (Less) alcohol consumption was measured with the question 'how often have you had an alcoholic drink during the last 12 months?' with responses ranging 1 (weekly) to 4 (never). Participants with a history of CVD or diabetes (self-reported) had cardiovascular disease (i.e., heart failure, coronary heart disease, angina, heart attack, stroke, and/or emphysema) or diabetes. Finally, having a history of another chronic disease (asthma, bronchitis or cancer) was also adjusted for.

\section{Analytic strategy}

First, we examined the descriptive statistics of the analytic sample. Following that, we investigated the correlations between all variables that were included in the regression models. Finally, we carried out linear regressions for CRP and fibrinogen separately. We ran our models in Stata/IC 15.1. All models accounted for the complex sampling design of Understanding Society. Analyses took into account stratification (by Government Office Region, population density and minority ethnic density) and non-independence of observations due to cluster sampling (individuals within households and households within postal sectors) (Asparouhov \& Muthen, 2006). 
Two models (Model 1 and Model 2) were run each for CRP and fibrinogen testing longitudinal (where the physical neighbourhood variables were measured at wave $1^{4}$ and inflammation at wave 2) associations, resulting in a total of 4 models. Model 1 tests whether there are effects of neighbourhood $\mathrm{NO}_{2}$ and greenspace on CRP and fibrinogen. Model 2 adjusts for the confounders including neighbourhood deprivation, urbanicity, age, gender, degree, marital status, housing tenure, household composition, BMI, smoking status, alcohol consumption, CVD or diabetes, and asthma, bronchitis or cancer. We report the regression coefficients for neighbourhood $\mathrm{NO}_{2}$ and greenspace for a 1-unit increase and a 10-unit increase. For $\mathrm{NO}_{2}$, this refers to an increase in 1 and $10 \mu \mathrm{g} / \mathrm{m}^{3}$ respectively and for greenspace, this refers to a 1 and 10 percentage point-increase, respectively.

Our $\mathrm{NO}_{2}$ variable was measured at LSOA-level and our greenspace indicator was measured at ward-level. Wards are larger than LSOAs and although LSOAs and wards overlap roughly $85 \%$, they do not do so perfectly. To check that our findings were robust to utilising the same exact geography for our $\mathrm{NO}_{2}$ and greenspace variables, we also tested the aforementioned relationships in the sample of residents in England only, where we had a measure of LSOA-level greenspace from GLUD (Office of the Deputy Prime Minister, 2005). We report these results briefly below in the text (tables are available upon request from the authors).

\section{Results}

\section{Descriptives}

Table 1 contains the descriptive analysis of all study variables. In the sample, participants were living in areas with an average of 53\%-56\% greenspace and with $\mathrm{NO}_{2}$

\footnotetext{
${ }^{4}$ As only 278 participants in our sample of 8,179 changed LSOA between waves 1 and 2, there was not enough variation in neighbourhood exposures over time in our sample (and power) to capture exposures longitudinally. Moreover, those who changed LSOA moved to similar neighbourhoods.
} 
levels just below the legal limit of $40 \mu \mathrm{g} / \mathrm{m}^{3}$. Area deprivation levels were close to average and the majority of participants were living in urban areas (76-79\%). In addition, around onethird of participants had a university degree (36\%) and the majority were married (57\%), owned a home (71\%) and were not living alone (80\%). Regarding health-related behaviours, only around 19\% reported being current smokers, and more than half reported drinking alcohol on a weekly basis (60\%). Around $29 \%$ had a BMI in the normal range. Furthermore, the majority of the participants reported that they were not suffering from CVD or diabetes $(89 \%)$ or other chronic conditions $(89-99 \%)$.

Statistically significant, albeit weak, correlations (Table 2) were found between the main variables of the study. CRP (measured at wave 2) is associated with greenspace at both waves and with $\mathrm{NO}_{2}$ at wave 2. Fibrinogen (measured at wave 2) is associated with $\mathrm{NO}_{2}$ at wave 1 only. Since $\mathrm{NO}_{2}$ and greenspace had moderate correlations across waves of -.58 to -.64, in regression models, we tested for multicollinearity problems but the variance inflation factor (VIF) values were less than 4 for all independent variables in the fully adjusted models.

Table 1

Descriptive statistics of the main variables of the study $(n=8,179)$

\begin{tabular}{|c|c|c|}
\hline & \multicolumn{2}{|c|}{ Continuous } \\
\hline & Mean & SD \\
\hline CRP $\log (\mathrm{mg} / \mathrm{l})$ & 0.31 & 0.92 \\
\hline Fibrinogen $\log (\mathrm{g} / \mathrm{L})$ & 1.01 & 0.21 \\
\hline $\mathrm{NO}_{2}\left(\mu \mathrm{g} / \mathrm{m}^{3}\right)$ at wave 1 & 37.33 & 7.40 \\
\hline $\mathrm{NO}_{2}\left(\mu \mathrm{g} / \mathrm{m}^{3}\right)$ at wave 2 & 36.73 & 7.37 \\
\hline Greenspace $(\%)$ at wave 1 & 53.38 & 26.43 \\
\hline Greenspace (\%) at wave 2 & 56.24 & 25.94 \\
\hline Area deprivation wave 1 (z-scores) & -0.52 & 2.84 \\
\hline Area deprivation wave 2 (z-scores) & -0.02 & 3.06 \\
\hline Higher BMI & 24.61 & 5.78 \\
\hline Age & 50.90 & 16.63 \\
\hline
\end{tabular}




\begin{tabular}{|c|c|c|}
\hline & $\mathrm{n}$ & $\%$ \\
\hline \multicolumn{3}{|l|}{ Gender } \\
\hline Male & 3,590 & 44.5 \\
\hline Female & 4,589 & 55.5 \\
\hline \multicolumn{3}{|l|}{ Education } \\
\hline Degree & 2,975 & 36.2 \\
\hline Other & 5,199 & 63.8 \\
\hline \multicolumn{3}{|l|}{ Marital status } \\
\hline Partnered & 4,908 & 57.0 \\
\hline Not partnered & 3,271 & 43.0 \\
\hline \multicolumn{3}{|l|}{ Housing tenure } \\
\hline Owns house/flat & 6,225 & 71.4 \\
\hline Does not own & 1,944 & 28.6 \\
\hline \multicolumn{3}{|l|}{ Household composition } \\
\hline Living alone & 1,824 & 19.9 \\
\hline Living with people & 6,355 & 80.1 \\
\hline \multicolumn{3}{|l|}{ Current smoker } \\
\hline Yes & 1,578 & 19.3 \\
\hline No & 6,600 & 80.7 \\
\hline \multicolumn{3}{|l|}{ Alcohol consumption } \\
\hline Weekly & 4,435 & 60.4 \\
\hline Monthly & 1,061 & 14.4 \\
\hline Less often than month & 1,295 & 17.6 \\
\hline Never & 555 & 7.6 \\
\hline \multicolumn{3}{|c|}{ Cardiovascular disease or diabetes } \\
\hline Yes & 977 & 11.0 \\
\hline No & 7,202 & 89.0 \\
\hline \multicolumn{3}{|l|}{ Asthma } \\
\hline Yes & 846 & 10.3 \\
\hline No & 7,333 & 89.7 \\
\hline \multicolumn{3}{|l|}{ Bronchitis } \\
\hline Yes & 129 & 1.4 \\
\hline No & 8,050 & 98.6 \\
\hline \multicolumn{3}{|l|}{ Cancer } \\
\hline Yes & 192 & 2.0 \\
\hline No & 7,987 & 98.0 \\
\hline \multicolumn{3}{|l|}{ Urbanicity at wave 1} \\
\hline Urban & 6,246 & 79.0 \\
\hline Rural & 1,933 & 21.0 \\
\hline \multicolumn{3}{|l|}{ Urbanicity at wave 2} \\
\hline Urban & 6,240 & 76.3 \\
\hline Rural & 1,936 & 23.7 \\
\hline
\end{tabular}


Table 2

Correlations between the main study variables

\begin{tabular}{|c|c|c|c|c|c|}
\hline & 1. & 2. & 3. & 4. & 5. \\
\hline 1. CRP $\log (\mathrm{mg} / \mathrm{l})$ & 1 & & & & \\
\hline 2. Fibrinogen $\log (\mathrm{g} / \mathrm{L})$ & $.39^{* * *}$ & 1 & & & \\
\hline 3. $\mathrm{NO}_{2}\left(\mu \mathrm{g} / \mathrm{m}^{3}\right)$ wave 1 & .02 & $.04^{* * *}$ & 1 & & \\
\hline 4. $\mathrm{NO}_{2}\left(\mu \mathrm{g} / \mathrm{m}^{3}\right)$ wave 2 & $.02^{*}$ & -.02 & $.80^{* * *}$ & 1 & \\
\hline 5. Greenspace $(\%)$ wave 1 & $-.03^{* *}$ & -.01 & $-.58^{* * *}$ & $-.64^{* * *}$ & 1 \\
\hline 6. Greenspace $(\%)$ wave 2 & $-.03^{* *}$ & -.01 & $-.58^{* * *}$ & $-.64^{* * *}$ & $.98^{* * *}$ \\
\hline
\end{tabular}




\section{Linear regression models}

Relationships between neighbourhood air pollution and greenspace with CRP and fibrinogen in England and Wales

In model 1 (Table 3), neither $\mathrm{NO}_{2}$ nor greenspace were significant predictors of $\mathrm{CRP}^{5}$. In model 2, participants in more deprived areas had higher CRP levels. Older participants, females, those who did not own their home, those who had higher BMI, those who smoked and those who had a history of bronchitis had higher CRP levels. Surprisingly, suffering from CVD or diabetes was associated with lower levels of CRP, perhaps due to anti-inflammatory or other medications. The largest effect sizes, according to the standardised coefficients in model 2 (Table 3), were of BMI $(\beta=.31)$ and age $(\beta=.15)$. All other significant predictors had standardised coefficients with absolute values ranging .03 to .08.

With regard to fibrinogen (Table 4), model 1 showed that $\mathrm{NO}_{2}$ only was significantly related to fibrinogen $(b=.001, p<.05)$ in the expected direction. This association was robust to covariates in model $2(b=.002, p<.01)$.

Additionally, living in a more deprived area, being female, not having a university degree, having a higher BMI, smoking and consuming less alcohol were related to higher levels of fibrinogen. The largest standardised coefficients in model 2 (Table 4), were of BMI $(\beta=.20)$ and age $(\beta=.27)$. Being female and being a smoker had a similar effect size $(\beta=.11$ and $\beta=.13$, respectively) and less alcohol consumption had an effect size of .08 . The

\footnotetext{
${ }^{5}$ To assess whether our null findings for air pollution and greenspace on CRP were due to subgroup differences washing out our main effects of air pollution and greenspace, we tested whether gender, smoking status and lung-related diseases (asthma, bronchitis) moderated their effects on CRP. We did not find any significant moderator effects.
} 
coefficient for neighbourhood $\mathrm{NO}_{2}(\beta=.06)$ was smaller in comparison but twice as large as that for having a university degree $(\beta=-.03)$.

Also, to check whether our results would change if we included only those who stayed in their neighbourhoods and did not therefore have varying levels of exposure to air pollution and greenery over time because of changes in their residential location, we ran our models without those who moved area (LSOA) between the two waves $(n=278)$ thereby including only non-movers. Our results were the same. These results are available upon request. The sample of movers is small which limits the power to detect differences in inflammation due changes in exposures. Hence we did not run the analyses for movers separately. Moreover, we tested whether neighbourhood deprivation moderated the association between neighbourhood nitrogen dioxide level and inflammation by adding interaction terms to the models. These were not significant.

We carried out an additional robustness check. The urbanicity variable does not capture the nuances of urban areas across England and Wales, where we might see high levels of air pollution and low levels of greenery in wealthy neighbourhoods of major cities such as London. Therefore, we tested whether adding a variable that measures whether the cohort member lives in London or not (from the Government Office Region variable) alters the significant association between $\mathrm{NO}_{2}$ and fibrinogen and it does not. What is more, it was not associated with fibrinogen or CRP. Results are available upon request.

Relationships between neighbourhood air pollution and greenspace with CRP and fibrinogen in England only

The results for the England sample were the same as those for participants in England and Wales. Specifically, LSOA-level $\mathrm{NO}_{2}$ and greenspace in England did not predict CRP 
significantly. With regard to fibrinogen, model 1 showed that, again, only $\mathrm{NO}_{2}$ was significantly (and positively) associated with fibrinogen $(b=.001, p<.05)$ and this relationship was robust to covariates in model $2(b=.002, p<.01)$. 
Table 3

Unstandardised and standardised regression coefficients (and standard errors) for CRP at wave 2 (longitudinal)

\begin{tabular}{|c|c|c|c|c|c|c|c|c|}
\hline \multirow[t]{2}{*}{ Predictors } & \multicolumn{4}{|c|}{ Model 1} & \multicolumn{4}{|c|}{ Model 2} \\
\hline & $\begin{array}{l}\text { Coefficient(SE) } \\
\text { 1-unit increase }\end{array}$ & $\begin{array}{l}\text { Coefficient(SE) } \\
\text { 10-unit increase }\end{array}$ & Beta & 95\% C.I. & $\begin{array}{l}\text { Coefficient(SE) } \\
\text { 1-unit increase }\end{array}$ & $\begin{array}{l}\text { Coefficient(SE) } \\
\text { 10-unit increase }\end{array}$ & Beta & 95\% C.I. \\
\hline $\mathrm{NO}_{2}\left(\mu \mathrm{g} / \mathrm{m}^{3}\right)$ (wave 1$)$ & $-0.001(0.02)$ & $-0.01(0.20)$ & -.008 & {$[-0.003,0.003]$} & $-0.001(0.002)$ & $-0.01(0.20)$ & -.008 & {$[-0.005,0.003]$} \\
\hline Greenspace (\%) (wave 1) & $-0.001(0.01)$ & $-0.01(0.10)$ & -.025 & {$[-0.002,0.0003]$} & $-0.001(0.001)$ & $-0.01(0.10)$ & -.017 & {$[-0.002,0.001]$} \\
\hline Deprivation (z-score) (wave 1) & & & & & $0.022 * * *(0.006)$ & & .067 & {$[0.011,0.033]$} \\
\hline Urbanicity (wave 1) & & & & & $-0.019(0.038)$ & & -.009 & {$[-0.093,0.055]$} \\
\hline Age & & & & & $0.009 * * *(0.001)$ & & .147 & {$[0.007,0.011]$} \\
\hline Female & & & & & $0.132 * * *(0.023)$ & & .070 & {$[0.086,0.177]$} \\
\hline Higher degree & & & & & $-0.050 *(0.027)$ & & -.026 & {$[-0.103,0.003]$} \\
\hline Partnered & & & & & $-0.055(0.034)$ & & -.029 & {$[-0.122,0.012]$} \\
\hline Owns home & & & & & $-0.097 * *(0.035)$ & & -.045 & {$[-0.166,-0.028]$} \\
\hline Living alone & & & & & $-0.048(0.042)$ & & -.022 & {$[-0.130,0.034]$} \\
\hline Higher BMI & & & & & $0.050 * * *(0.002)$ & & .310 & {$[0.046,0.054]$} \\
\hline Current smoker & & & & & $0.085^{* * *}(0.018)$ & & .069 & {$[0.050,0.120]$} \\
\hline Less alcohol consumption & & & & & $0.018(0.013)$ & & .020 & {$[-0.007,0.044]$} \\
\hline CVD & & & & & $-0.100 *(0.041)$ & & -.035 & {$[-0.180,-0.203]$} \\
\hline Asthma & & & & & $0.078(0.043)$ & & .026 & {$[-0.006,0.163]$} \\
\hline Bronchitis & & & & & $0.335^{* *}(0.104)$ & & .045 & {$[0.130,0.540]$} \\
\hline Cancer & & & & & $0.081(0.084)$ & & .014 & {$[-0.083,0.247]$} \\
\hline Constant & $0.390(0.101)$ & & -.011 & {$[-0.033,0.384]$} & $-1.549 * * *(0.140)$ & & .002 & {$[-1.823,-1.274]$} \\
\hline
\end{tabular}

Note. ${ }^{*} p<.05 ;{ }^{* *} p<.01 . \mathrm{CVD}=$ cardiovascular disease; BMI= Body Mass Index. 
Table 4

Unstandardised and standardised regression coefficients (and standard errors) for fibrinogen at wave 2 (longitudinal)

\begin{tabular}{|c|c|c|c|c|c|c|c|c|}
\hline \multirow[t]{2}{*}{ Predictors } & \multicolumn{4}{|c|}{ Model 1} & \multicolumn{4}{|c|}{ Model 2} \\
\hline & $\begin{array}{l}\text { Coefficient(SE) } \\
\text { 1-unit increase }\end{array}$ & $\begin{array}{l}\text { Coefficient(SE) } \\
\text { 10-unit increase }\end{array}$ & Beta & 95\% C.I. & $\begin{array}{l}\text { Coefficient(SE) } \\
\text { 1-unit increase }\end{array}$ & $\begin{array}{l}\text { Coefficient(SE) } \\
10 \text {-unit increase }\end{array}$ & Beta & 95\% C.I. \\
\hline $\mathrm{NO}_{2}\left(\mu \mathrm{g} / \mathrm{m}^{3}\right)($ wave 1$)$ & $0.001 *(0.001)$ & $0.01 *(0.01)$ & $.045^{*}$ & {$[0.0003,0.003]$} & $0.002 * * *(0.001)$ & $0.02 * * *(0.01)$ & .059 & {$[0.001,0.003]$} \\
\hline Greenspace (\%) (wave 1) & $0.0002(0.0002)$ & $0.002(0.002)$ & .021 & {$[-0.0001,0.001]$} & $0.0001(0.0002)$ & $0.001(0.002)$ & .008 & {$[-0.0003,0.004]$} \\
\hline Deprivation (z-score) (wave 1) & & & & & $0.003 *(0.001)$ & & .039 & {$[0.00002,0.006]$} \\
\hline Urbanicity (wave 1) & & & & & $-0.017(0.009)$ & & -.034 & {$[-0.035,0.0001]$} \\
\hline Age & & & & & $0.004 * * *(0.0002)$ & & .257 & {$[0.003,0.004]$} \\
\hline Female & & & & & $0.047 * * *(0.006)$ & & .109 & {$[0.036,0.058]$} \\
\hline Higher degree & & & & & $-0.014 *(0.006)$ & & -.031 & {$[-0.026,-0.001]$} \\
\hline Partnered & & & & & $0.005(0.009)$ & & .012 & {$[-0.012,0.022]$} \\
\hline Owns home & & & & & $-0.008(0.008)$ & & -.016 & {$[-0.024,0.008]$} \\
\hline Living alone & & & & & $0.009(0.010)$ & & .016 & {$[-0.010,0.027]$} \\
\hline Higher BMI & & & & & $0.008 * * *(0.001)$ & & .199 & {$[0.006,0.009]$} \\
\hline Current smoker & & & & & $0.032 * * *(0.004)$ & & .108 & {$[0.023,0.040]$} \\
\hline Less alcohol consumption & & & & & $0.018 * * *(0.003)$ & & .086 & {$[0.012,0.024]$} \\
\hline CVD & & & & & $-0.008(0.010)$ & & -.011 & {$[-0.026,0.012]$} \\
\hline Asthma & & & & & $0.015(0.010)$ & & .021 & {$[-0.006,0.035]$} \\
\hline Bronchitis & & & & & $0.002(0.026)$ & & -.001 & {$[-0.048,0.053]$} \\
\hline Cancer & & & & & $0.006(0.025)$ & & .004 & {$[-0.044,0.056]$} \\
\hline Constant & $0.946 * * *(0.027)$ & & $-.042 * * *$ & {$[0.894,0.999]$} & $0.424 * * *(0.037)$ & & -.012 & {$[0.351,0.497]$} \\
\hline
\end{tabular}

Note. ${ }^{*} p<.05 ;{ }^{* *} p<.01 . \mathrm{CVD}=$ cardiovascular disease; BMI= Body Mass Index. Time $1=$ wave 1 , time $2=$ wave 2 or 3. 


\section{Discussion}

This study explored the roles of neighbourhood $\mathrm{NO}_{2}$ and greenspace in inflammatory markers among adults in a large-scale longitudinal sample in England and Wales. The analyses adjusted for a range of key confounders including neighbourhood deprivation and urbanicity and individual socio-economic background and health-related conditions and behaviours.

A key finding was that an increase in $\mathrm{NO}_{2}$ concentration was significantly related to fibrinogen measured a year later, providing some support for the proposed hypothesis that traffic-related air pollution causes inflammation. This may indicate the presence of a longerterm rather than short-term effect of $\mathrm{NO}_{2}$. The literature on air pollution and inflammatory markers shows mixed results and the variation in the air pollutants and inflammatory markers that are explored in the different studies make it difficult to compare findings. Some studies showed links between some air pollutants (but not $\mathrm{NO}_{2}$ ) and fibrinogen (Chuang et al., 2007) and others found no relationship between a range of air pollutants and fibrinogen in adults (Forbes et al., 2009; Lanki et al., 2015; Rudez et al., 2009; Viehmann et al., 2016). Chaparro et al. (2018) found links between both neighbourhood-level air pollution and greenspace and CRP using US cross-sectional data. However, they used a sample of adults in England, Wales as well as Scotland and they employed a ward-level indicator of air pollution from 1999-2003 whereas we used a smaller area indicator (LSOA) of air pollution from 2009-2011, which is more aligned to the years of waves 1-2 in US and also more appropriate for capturing air pollution exposure around the home. They also did not look at fibrinogen. Therefore it is difficult to compare our results with theirs. Nevertheless, the studies that have examined air pollutants and inflammation appear to be more likely to show an association when exposure over a long-term period is assessed, although none of these longitudinal studies found links with fibrinogen (Li et al., 2012) and none of those that included a measure of $\mathrm{NO}_{2}$ found that 
$\mathrm{NO}_{2}$ was related to inflammatory markers. Viehmann et al.'s (2015) longitudinal analysis of German cohort data found an association between exposure to PM - on average, measured a year prior to blood draw - and elevated CRP but not fibrinogen. Their measure of PM at cohort members' residences was identified on a $1 \mathrm{~km}^{2}$ grid which is a more immediate area around the home than what wards and LSOAs capture. They also adjusted for short-term exposures to PM in their models. Although they looked at $\mathrm{PM}$ and not $\mathrm{NO}_{2}$, it is possible that wards and LSOAs are not on a fine enough scale to accurately pick up exposure to pollutants in the neighbourhood. Another longitudinal study that analysed data on adults aged 45-84 living in urban areas of the USA and participating in the Multi-Ethnic Study of Atherosclerosis (Hajat et al., 2015) found that long-term exposure to higher concentrations of PM (but not $\mathrm{NO}_{2}$ ) assessed over four waves from 2000 to 2012 was associated with elevated IL-6 but not CRP or fibrinogen. Only short-term (measured on the day of blood draw) exposure to increased PM was related to higher CRP and fibrinogen. Moreover, Thompson et al. (2009) found an association between $\mathrm{SO}_{2}$ and ozone and IL-6 but not between any pollutants (including $\mathrm{NO}_{2}$ ) and fibrinogen. Future research should explore the role of other pollutants alongside $\mathrm{NO}_{2}$ when examining effects on inflammation to ascertain whether our $\mathrm{NO}_{2}$-fibrinogen results remain when adjusting for other pollutant levels.

The association we found was robust to adjustment for neighbourhood greenspace, which is lower in areas with more pollution, especially in urban settlements. Few studies have included these two measures of the neighbourhood physical environment together despite their close inverse relationship. This association was also robust to controls for neighbourhood deprivation, which aimed to factor out the economic, social and health-related characteristics of the neighbourhood and its residents, and a host of individual socioeconomic and health-related variables shown in the literature to be associated with neighbourhood selective sorting as well as inflammation. Nevertheless, the size of the association we 
identified for pollution is small relative to that of the associations with the individual characteristics examined. BMI and age had the largest associations, two of the main risk factors for inflammation (Goldberg \& Dixit, 2016; Shelton \& Miller, 2010).

On the other hand, our expectation that greenspace, as a health-enhancing factor, would be related to lower inflammation was not supported by this research. It may be the timing of our measurement of greenspace that affected the results, as the only available area greenspace measure is from 1999-2003 (MEDix) and waves 1 to 2 in Understanding Society took place across 2009 to 2012. Nevertheless, although air pollution can fluctuate substantially over time, the amount of greenspace is less variable over a number of years. In addition, we have not been able to capture the extent to which cohort members use greenspace, or even view it, in their neighbourhoods, which may be a requirement in order to lower inflammation levels. Direct measures of the use of greenspace may be worth exploring in relation to inflammation including how often people visit green spaces (and of what quality) and for how long, and what they do in them.

Our findings about the association between $\mathrm{NO}_{2}$ exposure in the neighbourhood and inflammation and the lack of relationship between greenspace in the neighbourhood and inflammation may suggest that area policies should focus on reducing air pollution for public health benefits. The UK government has made strategic plans (https://consult.defra.gov.uk/environmental-quality/clean-air-strategy-consultation/) and has begun to take steps to implement initiatives to reduce $\mathrm{NO}_{2}$ emissions in urban areas such as London (e.g., by issuing high pollution alerts or charges for the dirtiest vehicles) but it will probbaly take a number of years before there are significant reductions in emission levels. Our findings may also have implications for individuals living in high-pollution areas as they attempt to mitigate exposure to pollutants until the broader changes have an effect. For example, individuals who walk to work or school might choose to take routes involving 
quieter roads with less traffic. Nevertheless, we must be cautious about the implications of this research given the very modest associations for $\mathrm{NO}_{2}$ that we identified and the correlational nature of our study which prevents us from being able to make any claims about air pollution causing inflammation. Further research should examine effects of longer-term exposures to neighbourhood air pollution and greenspace including ideally more than one measure of inflammation. Moreover, research should look at whether inflammation mediates the association between air pollution and health, since it is considered to be a key pathway linking the two.

Our findings must also be considered in the light of additional limitations. Our findings regarding neighbourhood-level pollution and fibrinogen may be due to other factors such as traffic noise which we could not adjust for in this study. Extant studies of air pollution and inflammation in adults, including Chaparro et al.'s (2018), did not adjust for noise pollution either. Future research should address this. Additionally, we could not capture aspects of the indoor environment in this study. For example, in addition to spending time at home and in their neighbourhoods, most adults spend a substantial amount of time at work where air pollution and noise exposures may differ depending on the occupation. We also could not capture indoor air pollutants in this study. Air pollutants generated indoors such as those from activities like smoking, cooking, heating and use of paints, varnishes and cleaning products may adversely affect health outcomes. Indoor air pollution could also confound associations between outdoor air pollution and inflammation. Lastly, we were unable to account for spillover effects from adjacent areas.

Inflammation is a key proposed pathway from neighbourhood physical factors including air pollution and greenspace - to health outcomes. Using a large-scale longitudinal sample of adults living in England and Wales, we found that neighbourhood-level exposure to $\mathrm{NO}_{2}$, a traffic-related pollutant known to have harmful effects on health, was related to 
later elevated fibringen, even after adjusting for neighbourhood greenspace and deprivation as well as important individual-level confounders. Neighbourhood-level greenspace was not associated with CRP or fibrinogen. Further research should explore the effects of the built environment, more comprehensively described, over a longer period of time and with additional repeated measures of inflammation.

\section{References}

Alcock, I., White, M. P., Wheeler, B. W., Fleming, L. E., \& Depledge, M. H. (2014). Longitudinal effects on mental health of moving to greener and less green urban areas. Environmental Science and Technology, 48(2), 1247-1255. doi: $10.1021 / \mathrm{es} 403688 \mathrm{w}$

Beckett, K. P., Freer-Smith, P. H., \& Taylor, G. (1998). Urban woodlands: Their role in reducing the effects of particulate pollution. Environmental Pollution, 99(3), 347-360. doi: 10.1016/S0269-7491(98)00016-5

Brunner, E. J., Kivimäki, M., Witte, D. R., Lawlor, D. A., Smith, G. D., Cooper, J. A., \& Shah, T. (2008). Inflammation, insulin resistance, and diabetes-Mendelian randomization using CRP haplotypes points upstream. PLoS Medicine, 5(8), e155. doi: 10.1371/journal.pmed.0050155

Carstairs, V., \& Morris, R. (1989). Deprivation, mortality and resource allocation. Journal of Public Health, 11(4), 364-372.

Chaparro, M. P., Benzeval, M., Richardson, E., \& Mitchell, R. (2018). Neighborhood deprivation and biomarkers of health in Britain: The mediating role of the physical environment. BMC Public Health, 18(1), 801. doi: 10.1186/s12889-018-5667-3

Chuang, K. J., Chan, C. C., Su, T. C., Lee, C. T., \& Tang, C. S. (2007). The effect of urban air pollution on inflammation, oxidative stress, coagulation, and autonomic 
dysfunction in young adults. American Journal of Respiratory and Critical Care Medicine, 176(4), 370-376. doi: 10.1164/rccm.200611-1627OC

Coombes, E., Jones, A. P., \& Hillsdon, M. (2010). The relationship of physical activity and overweight to objectively measured green space accessibility and use. Social Science and Medicine, 70(6), 816-822. doi: 1016/j.socscimed.2009.11.020

de Vries, S., Van Dillen, S. M., Groenewegen, P. P., \& Spreeuwenberg, P. (2013).

Streetscape greenery and health: stress, social cohesion and physical activity as mediators. Social Science and Medicine, 94, 26-33. doi:

10.1016/j.socscimed.2013.06.030

EEA, C. L. C (2000). European Environmental Agency. Commission of the European Community.

Ertek, S., \& Cicero, A. (2012). Impact of physical activity on inflammation: Effects on cardiovascular disease risk and other inflammatory conditions. Archives of Medical Science: $A M S, 8(5), 794$. doi: 10.5114/aoms.2012.31614

Forbes, L. J., Patel, M. D., Rudnicka, A. R., Cook, D. G., Bush, T., Stedman, J. R., \& Anderson, R. H. (2009). Chronic exposure to outdoor air pollution and markers of systemic inflammation. Epidemiology, 245-253. doi: 10.1097/EDE.0b013e318190ea3f

Freer-Smith, P. H., \& Broadmeadow, M. S. J. (1996). The improvement of urban air quality by trees. Arboriculture Research and Information Note-Department of the Environment (United Kingdom). 
Freer-Smith, P. H., Holloway, S., \& Goodman, A. (1997). The uptake of particulates by an urban woodland: Site description and particulate composition. Environmental Pollution, 95(1), 27-35. doi: 10.1016/S0269-7491(96)00119-4

Groenewegen, P. P., Zock, J. P., Spreeuwenberg, P., Helbich, M., Hoek, G., Ruijsbroek, A., \& Dijst, M. (2018). Neighbourhood social and physical environment and general practitioner assessed morbidity. Health \& Place, 49, 68-84. doi: 10.1016/j.healthplace.2017.11.006

Guarnieri, M., \& Balmes, J. R. (2014). Outdoor air pollution and asthma. The Lancet, 383(9928), 1581-1592. doi: 10.1016/S0140-6736(14)60617-6

Hajat, A., Allison, M., Diez-Roux, A. V., Jenny, N. S., Jorgensen, N. W., Szpiro, A. A., \& Kaufman, J. D. (2015). Long-term exposure to air pollution and markers of inflammation, coagulation, and endothelial activation: A repeat-measures analysis in the Multi-Ethnic Study of Atherosclerosis (MESA). Epidemiology (Cambridge, Mass.), 26(3), 310. doi: 10.1097/EDE.0000000000000267

Hartig, T., Mitchell, R., De Vries, S., \& Frumkin, H. (2014). Nature and health. Annual Review of Public Health, 35, 207-228. doi: 10.1146/annurev-publhealth-032013182443

Hoffmann, B., Moebus, S., Dragano, N., Stang, A., Möhlenkamp, S., Schmermund, A., \& Jöckel, K. H. (2009). Chronic residential exposure to particulate matter air pollution and systemic inflammatory markers. Environmental Health Perspectives, 117(8), 1302. doi: 10.1289/ehp.0800362 
Howren, M. B., Lamkin, D. M., \& Suls, J. (2009). Associations of depression with C-reactive protein, IL-1, and IL-6: A meta-analysis. Psychosomatic Medicine, 71(2), 171-186. doi: 10.1097/PSY.0b013e3181907c1b

Irwin, M. R., \& Cole, S. W. (2011). Reciprocal regulation of the neural and innate immune systems. Nature Reviews Immunology, 11(9), 625. doi: 10.1038/nri3042

Kiecolt-Glaser, J. K., Derry, H. M., \& Fagundes, C. P. (2015). Inflammation: Depression fans the flames and feasts on the heat. American Journal of Psychiatry, 172(11), 10751091. doi: 10.1176/appi.ajp.2015.15020152

Lanki, T., Hampel, R., Tiittanen, P., Andrich, S., Beelen, R., Brunekreef, B., \& Imboden, M. (2015). Air pollution from road traffic and systemic inflammation in adults: A crosssectional analysis in the European ESCAPE Project. Environmental Health Perspectives, 123(8), 785. doi: 10.1289/ehp.1408224

Li, Y., Rittenhouse-Olson, K., Scheider, W. L., \& Mu, L. (2012). Effect of particulate matter air pollution on C-reactive protein: A review of epidemiologic studies. Reviews on Environmental Health, 27(2-3), 133-149. doi: 10.1515/reveh-2012-0012

Lim, Y. H., Kim, H., Kim, J. H., Bae, S., Park, H. Y., \& Hong, Y. C. (2012). Air pollution and symptoms of depression in elderly adults. Environmental Health Perspectives, 120(7), 1023. doi: 10.1289/ehp.1104100

McFall, S. L., Conolly, A., \& Burton, J. (2014, March). Collecting biomarkers using trained interviewers. Lessons learned from a pilot study. In Survey research methods (Vol. 8, No. 1, pp. 57-66). doi: 10.18148/srm/2014.v8i1.5471 
Midouhas, E., Kokosi, T., \& Flouri, E. (2018). Outdoor and indoor air quality and cognitive ability in young children. Environmental Research, 161, 321-328. doi: 10.1016/j.envres.2017.11.026

Office of the Deputy Prime Minister (2005). Generalised Land Use Database statistics for England. London: ODPM Publications.

Mitchell, R. J., Richardson, E. A., Shortt, N. K., \& Pearce, J. R. (2015). Neighborhood environments and socioeconomic inequalities in mental well-being. American Journal of Preventive Medicine, 49(1), 80-84. doi: 10.1016/j.amepre.2015.01.017

Mukhopadhyay, S., \& Sahu, S. K. (2018). A Bayesian spatiotemporal model to estimate longterm exposure to outdoor air pollution at coarser administrative geographies in England and Wales. Journal of the Royal Statistical Society: Series A (Statistics in Society), 181(2), 465-486. doi: 10.1111/rssa.12299

Nowak, D., Jorres, R., Berger, J., Claussen, M., \& Magnussen, H. (1997). Airway responsiveness to sulfur dioxide in an adult population sample. American Journal of Respiratory and Critical Care Medicine, 156(4), 1151-1156. doi:

10.1164/ajrccm.156.4.9607025

Oudin, A., Forsberg, B., Adolfsson, A. N., Lind, N., Modig, L., Nordin, M., \& Nilsson, L. G. (2015). Traffic-related air pollution and dementia incidence in northern Sweden: A longitudinal study. Environmental Health Perspectives, 124(3), 306-312. doi: 10.1289/ehp.1408322

Perera, F. P., Tang, D., Wang, S., Vishnevetsky, J., Zhang, B., Diaz, D., \& Rauh, V. (2012). Prenatal polycyclic aromatic hydrocarbon (PAH) exposure and child behavior at age 67 years. Environmental Health Perspectives, 120(6), 921. doi: 10.1289/ehp.1104315 
Powe, N. A., \& Willis, K. G. (2004). Mortality and morbidity benefits of air pollution $\left(\mathrm{SO}_{2}\right.$ and $\left.\mathrm{PM}_{10}\right)$ absorption attributable to woodland in Britain. Journal of Environmental Management, 70(2), 119-128. doi: 10.1016/j.jenvman.2003.11.003

Richardson, E. A., \& Mitchell, R. (2010). Gender differences in relationships between urban green space and health in the United Kingdom. Social Science \& Medicine, 71(3), 568-575. doi: 10.1016/j.socscimed.2010.04.015

Richardson, E. A., Mitchell, R., Shortt, N. K., Pearce, J., \& Dawson, T. P. (2010). Developing summary measures of health-related multiple physical environmental deprivation for epidemiological research. Environment and Planning A, 42(7), 16501668. doi: $10.1068 / \mathrm{a} 42459$

Ridker, P. M., Buring, J. E., Cook, N. R., \& Rifai, N. (2003). C-reactive protein, the metabolic syndrome, and risk of incident cardiovascular events: an 8-year follow-up of 14719 initially healthy American women. Circulation, 107(3), 391-397. doi: 10.1161/01.cir.0000055014.62083.05

Ridker, P. M., Rifai, N., Rose, L., Buring, J. E., \& Cook, N. R. (2002). Comparison of Creactive protein and low-density lipoprotein cholesterol levels in the prediction of first cardiovascular events. New England Journal of Medicine, 347(20), 1557-1565. doi: 10.1056/NEJMoa021993

Roe, J. J., Thompson, C. W., Aspinall, P. A., Brewer, M. J., Duff, E. I., Miller, D., \& Clow, A. (2013). Green space and stress: evidence from cortisol measures in deprived urban communities. International Journal of Environmental Research and Public Health, 10(9), 4086-4103. doi: 10.3390/ijerph10094086 
Rook, G. A. (2013). Regulation of the immune system by biodiversity from the natural environment: an ecosystem service essential to health. Proceedings of the National Academy of Sciences, 110(46), 18360-18367. doi: 10.1073/pnas.1313731110

Rudež, G., Janssen, N. A., Kilinc, E., Leebeek, F. W., Gerlofs-Nijland, M. E., Spronk, H. M., \& de Maat, M. P. (2009). Effects of ambient air pollution on hemostasis and inflammation. Environmental Health Perspectives, 117(6), 995. doi: 10.1289/ehp.0800437

Sesso, H. D., Buring, J. E., Rifai, N., Blake, G. J., Gaziano, J. M., \& Ridker, P. M. (2003). Creactive protein and the risk of developing hypertension. Jama, 290(22), 2945-2951. doi: 10.1001/jama.290.22.2945

Shelton, R. C., \& Miller, A. H. (2010). Eating ourselves to death (and despair): The contribution of adiposity and inflammation to depression. Progress in Neurobiology, 91(4), 275-299. doi: 10.1016/j.pneurobio.2010.04.004

Thompson, A. M., Zanobetti, A., Silverman, F., Schwartz, J., Coull, B., Urch, B., \& Gold, D. R. (2009). Baseline repeated measures from controlled human exposure studies: associations between ambient air pollution exposure and the systemic inflammatory biomarkers IL-6 and fibrinogen. Environmental Health Perspectives, 118(1), 120-124. doi: 10.1289/ehp.0900550

Thompson, C. W., Roe, J., Aspinall, P., Mitchell, R., Clow, A., \& Miller, D. (2012). More green space is linked to less stress in deprived communities: Evidence from salivary cortisol patterns. Landscape and Urban Planning, 105(3), 221-229. doi: 10.1016/j.landurbplan.2011.12.015 
Twohig-Bennett, C., \& Jones, A. (2018). The health benefits of the great outdoors: A systematic review and meta-analysis of greenspace exposure and health outcomes.. Environmental Research, 166, 628-637. doi: 10.1016/j.envres.2018.06.030

Viehmann, A., Hertel, S., Fuks, K., Eisele, L., Moebus, S., Möhlenkamp, S., ... \& Hoffmann, B. (2015). Long-term residential exposure to urban air pollution, and repeated measures of systemic blood markers of inflammation and coagulation. Occupational and Environmental Medicine, 72(9), 656-663.

Ward Thompson, C., \& Aspinall, P. A. (2011). Natural environments and their impact on activity, health, and quality of life. Applied Psychology: Health and Well-Being, 3(3), 230-260. doi: 10.1111/j.1758-0854.2011.01053.x

Wheeler, B. (2014). Carstairs Index 2011 for LSOAs. Colchester, Essex: UK Data Archive.

Zupancic, T., Westmacott, C., \& Bulthuis, M. (2015). The impact of green space on heat and air pollution in urban communities: A meta-narrative systematic review. Vancouver, BC, Canada: David Suzuki Foundation. 